\title{
Membaca Pesan Komandan KRI Nanggala-402
}

Oleh: Pardomuan Gultom

(dimuat di Koran Analisa, edisi Jumat, 28 Mei 2021. Link versi e-paper:

https://analisadaily.com/e-paper/2021-05-28/files/assets/basic-html/index.html\#17)

Peristiwa tenggelamnya (submarine sunk) KRI Nanggala-402 selain menyisakan duka yang dalam bagi 53 keluarga prajurit Korps Hiu Kencana, keluarga besar TNI, dan bangsa Indonesia, terdapat semacam pesan penting yang pernah disampaikan oleh Komandan KRI Nanggala-402, Letkol Laut (P) Heri Oktavian kepada salah seorang wartawan Kompas, Edna C. Pattisina pada tahun 2020 silam (Kompas, 25/4).

Heri berharap, para pembuat keputusan benar-benar memikirkan TNI dan prajuritnya, bukan hanya "asal bapak senang" demi pangkat dan kursi yang enak atau keuntungan material. Ia juga sempat menyampaikan perihal pembelian kapal selam bekas. Heri berharap Korps Hiu Kencana dapat memiliki kapal selam yang mumpuni. Punya kemampuan tempur.

Dari pesan tersebut, penting kiranya membahas perkembangan kebijakan pertahanan nasional dan hubunganya dengan penyempurnaan alutsista kita.

\section{Pertahanan Negara}

Pada Pembukaan Undang-Undang Dasar 1945 telah ditegaskan bahwa tujuan dari kepentingan nasional kita, yaitu melindungi segenap bangsa Indonesia dan seluruh tumpah darah Indonesia. Melindungi yang dimaksud adalah memberi perlindungan dari ancaman yang datangnya dari luar maupun dari dalam Indonesia sendiri. Dengan demikian, upaya perlindungan terhadap segenap bangsa Indonesia dan seluruh tumpah darah Indonesia membutuhkan strategi pertahanan nasional yang kuat dari kedua ancaman tersebut. 
Indonesia memiliki luas wilayah sekitar $5.219 .270 \mathrm{~km}^{2}$, dengan jumlah 17.508 pulau dan sekitar 6000 pulau diantaranya berpenghuni. Luas daratan sekitar $1.919 .270 \mathrm{~km}^{2}$ dikelilingi oleh sekitar 3.3 juta $\mathrm{km}^{2}$ laut teritorial yang merupakan 2/3 dari total luas wilayah Indonesia. Jarak dari utara ke selatan adalah sekitar $1.770 \mathrm{~km}$ dan $5.152 \mathrm{~km}$ dari Timur ke Barat atau seperdelapan dari keliling dunia. Dan saat ini jumlah penduduk Indonesia sebesar 270 juta jiwa (BPS, 2020).

Hans J. Morgenthau dalam bukunya Politics Among Nation: The Struggle for Power and Peace (1978) mengatakan bahwa kepentingan nasional memiliki 3 (tiga) konsep penting, yakni perlindungan terhadap identitas fisik (teritorial), politik, dan kultur (linguistik dan sejarah).

Perlindungan terhadap identitas fisik (teritorial) inilah yang merupakan konsep utama dari sistem pertahanan negara, dimana pasca Orde baru menjadi produk undang-undang, yaitu Undang-Undang No. 3 Tahun 2002 tentang Pertahanan Negara dan Peraturan Presiden No. 41 Tahun 2010 tentang Kebijakan Umum Pertahanan Negara Tahun 2010-2014 sebagai instrumen pelaksananya.

\section{Tren Kekuatan Pertahanan}

Pada tahun 2020, ketersediaan personel militer di Indonesia kurang lebih 800.000 personel, dengan 400.000 personel aktif dan 400.000 personel cadangan. Jumlah personel militer aktif di Indonesia menempati uratan ke-13 dunia sedangkan personel cadangan menempati urutan ke-16 dunia. 
Pada 3 Maret 2021 lembaga riset kekuatan militer dunia, Global Fire Power, merilis bahwa kekuatan militer Indonesia berada di posisi ke-16 dari 140 negara di dunia. Posisi ini tetap bertahan dari tahun 2020 yang lalu, dimana kekuatan udara berada pada urutan ke-28 di dunia dengan jumlah 462 pesawat yang terdiri atas 41 pesawat tempur, 39 pesawat serangan khusus, 54 pesawat angkut, 109 pesawat latih, 5 pesawat intai dan misi khusus, 177 helikopter, serta 16 helikopter tempur. Akan tetapi, khusus untuk jumlah kepemilikan pesawat tempur, Indonesia berada di urutan ke-48. Di tahun 2018 kita sempat menduduki posisi ke-15 (Tempo, 11/2/2019). Posisi ini menempatkan kita pada kekuatan militer yang terbesar di Asia Tenggara. Disusul Vietnam, Thailand, Malaysia, dan terakhir Singapura.

Di tahun 2020, Indonesia punya 133 tank dan 1.178 kendaraan tempur lapis baja. Namun, di wilayah Asia Tenggara, Vietnam menjadi negara yang memiliki tank paling banyak sehingga berada di urutan ke-10 kepemilikan tank di dunia,. Kita juga memiliki 153 artileri swagerak, 366 artileri tarik, serta 36 peluncur roket dengan urutan ke-57 dunia.

Di tahun 2020, kekuatan laut Indonesia memiliki 282 alutsista yang terdiri atas 7 kapal fregat, 24 kapal korvet, 5 kapal selam, 156 kapal patroli, dan 10 kapal penyapu ranjau dan menempati urutan ke-10 dunia Dengan hilangnya KRI Nanggala-402, berarti kapal selam yang dimiliki Indonesia tinggal 4 unit.

\section{Belanja Militer}


Kekuatan militer suatu negara dapat dililhat dari belanja militer. Selama satu dekade terakhir, jumlah anggaran belanja pemerintah untuk urusan pertahanan terus meningkat.

Jika memperhatikan data yang dipublikasi oleh Stockholm International Peace Research Institute (SIPRI) yang berbasis di Swedia, sejak tahun 1988 anggaran belanja militer Indonesia terus meningkat, dari $\mathrm{Rp} 2,2$ triliun meningkat menjadi $\mathrm{Rp}$ 8,9 triliun di tahun 1999. Dan di 2009, anggaran ini naik menjadi Rp 34,3 triliun.

Dari tahun 2010 hingga 2020 juga terjadi tren peningkatan. Pernah mengalami penurunan anggaran dari tahun 2015 ke tahun 2016 serta dari tahun 2017 ke 2018. Pada tahun 2015 anggaran belanja pertahanan adalah Rp 101,6 triliun. Angka tersebut turun menjadi Rp 98,2 triliun pada tahun 2016.

Sementara itu, pada tahun 2018 anggaran belanja militer Indonesia sebesar Rp 107 triliun, turun dari anggaran tahun 2017 sebesar Rp 17 triliun. Tahun 2019 mengalami peningkatan sekitar Rp. 15 triliun, yakni sebesar Rp 115,4 triliun. Di tahun 2020 juga mengalami peningkatan sekitar Rp. 2,5 triliun, yaitu sebesar Rp 117,9 triliun yang menempatkan Indonesia di posisi ke-31 dalam urusan belanja militer di dunia dan nomor dua di Asia Tenggara setelah Singapura (posisi 26). Dan di tahun 2021 mengalami peningkatan yang fantastis dari yang pernah ada sebelumnya, yakni sebesar Rp 136,9 triliun.

\section{Kebijakan Sistem Pertahanan}

Terdapat kebijakan Kekuatan Pokok Minimum (Minimum Essential Force/MEF) yang merupakan kebijakan optimalisasi alutsista yang lahir pada era SBY melalui Peraturan 
Presiden No. 41 Tahun 2010 tentang Kebijakan Umum Pertahanan Negara sebagai upaya peningkatan kemampuan mobilitas TNI dalam tiga matra, yakni darat, laut, dan udara.

MEF tahap kedua dikerjakan pada periode 2015-2019 dengan tujuan meningkatkan kemampuan kerjasama produksi serta pembangunan produk baru alutsista. MEF tahun 2021 ini sedang memasuki tahap ketiga, yakni fase 2019-2024. Panglima TNI Marsekal Hadi Tjanjanto menyebutkan bahwa kebijakan MEF hingga tahun 2019 telah mencapai 72 persen (PAL, 2020).

Lampiran Permenhan No. 19 Tahun 2012 mengulas persoalan pengadaan alutsista sebagai salah satu unsur MEF, selain sumber daya manusia, sarana pangkalan dan daerah latihan, industri pertahanan, organisasi, dan anggaran.

Di sisi lain untuk pengadaan dalam negeri, kemampuan industri pertahanan masih terbatas dalam memenuhi spesifikasi teknis yang dibutuhkan TNI. Pengadaan luar negeri menggunakan fasilitas Kredit Eksport (KE) yang memiliki birokrasi panjang dan lambatnya proses dari setiap simpul pengadaan. Hal ini menyebabkan pengadaan alutsista memerlukan waktu yang lama, sementara teknologi berkembang cepat, dan waktu penyerapan anggaran terbatas.

Pada tahapan ini penyelenggaran MEF melalui sistem pengadaan banyak menghadapi problematika dengan beberapa tahapan kepentingan yang pada akhirnya memperlambat proses eksekusi dan berujung pada tidak optimalnya operasional. Sementara alutsista semakin tidak laik pakai bahkan bisa membahayakan keselamatan manusia dan lingkungan. 
Dalam MEF terdapat pembangunan dan pengembangan organisasi yang perlu disesuaikan. Ketidaksinkronan antara kebijakan dan operasional di lapangan apabila dihadapkan pada kondisi kritis alutsista perlu adanya konsistensi dalam sistem penggantian alutsista tersebut, di samping itu sistem standardisasi militer dan kelaikan alutsista militer banyak yang belum terpenuhi (Lampiran Permenhan No. 19 Tahun 2012 hlm. 9).

Dengan demikian, tidaklah heran jika Komandan KRI Nanggala-402, Letkol Laut (P) Heri Oktavian memiliki harapan besar terhadap pembangunan alutsista yang kuat, maju, dan mandiri agar tercipta sistem pertahanan negara yang dapat melindungi segenap bangsa Indonesia dan seluruh tumpah darah Indonesia.

* Penulis adalah Mahasiswa konversi Sekolah Tinggi Ilmu Hukum (STIH) Graha Kirana/Alumnus Departemen Ilmu Politik FISIP USU 